\title{
«Veoir la rareté des peintures». El liderazgo de David Teniers II en la red económica artística del Siglo de Oro. Nuevas aportaciones en torno a su taller y clientes* \\ «Veoir la rareté des peintures». The Leadership of David Teniers II in the Artistic Economic Network of the Golden Century. New Information about his Workshop and Customers
}

\section{Raúl Romero Medina}

https://orcid.org/0000-0001-6129-1399

Universidad Complutense de Madrid

ESPAÑA

raul.romero.medina@ucm.es

\section{Jean-Louis Van Belle}

https://orcid.org/0000-0002-3746-5720

Centre International de Recherches Glyptographiques

BÉLGICA

cirg.be@gmail.com

[Hipogrifo, (issn: 2328-1308), 8.2, 2020, pp. 761-779]

Recibido: 13-03-2020 / Aceptado: 04-05-2020

DOI: http://dx.doi.org/10.13035/H.2020.08.02.44

Resumen. El 3 de diciembre de 1666 tenía lugar en Bruselas una venta particular de pinturas de David Teniers II (1610-1690). Por esta razón, llegaron al domicilio del pintor, donde estaba su taller, doce clientes ávidos de participar en ella y atraídos

* Este trabajo participa de los proyectos de investigación I+D Corte y cortes en el Tardogótico Hispano. Narrativa, memorias y sinergias en el lenguaje visual. REF: PGC2018-093822-B-I00 y Espacios de coleccionismo en la Casa de Austria 2: siglos XVI y XVII. REF: HAR2017-83094P. 
por la rareza y curiosidad de su paleta. Por razones gremiales Teniers parecía tener prohibida la venta, pero esta se llevó a cabo de forma privada, y se tomó testimonio de ella. El artículo intenta acercarse al estudio de estos documentos inéditos por cuanto nos permiten conocer no sólo aspectos de coleccionismo artístico, como sus clientes, sino el liderazgo de Teniers II en la red económica artística del Siglo de Oro.

Palabras clave. Red económica artística; David Teniers II; Bruselas; coleccionismo; clientes; taller, Siglo de Oro.

Abstract. On December 3, 1666 a private sale of paintings by David Teniers II (1610-1690) took place in Brussels. For this reason, they arrived at the home of the painter, where he had his workshop, twelve clients to participate in it and attracted by the rarity and curiosity of his palette. For guild reasons, Teniers seemed to be prohibited from selling, but the sale was carried out privately, not without taking testimony from it. The article seeks to approach the study of these unpublished documents because it allows us to know aspects of art collecting, such as its customers, and the leadership of Teniers in the artistic economic network of the Golden Century.

Keywords. Artistic economic network; David Teniers II; Brussels; Collecting; Customers; Workshop; Golden Century.

\section{INTRODUCCIÓN}

De entre los eslabones que formaban la cadena de cortes de la casa de los Habsburgo, la de Bruselas fue una de las más destacadas al ser uno de los ejes políticos y culturales más activos de la Europa del Siglo de Oro ${ }^{\top}$. La ciudad del Manneken Pis venía despuntando desde el primer florecimiento del arte flamen$\mathrm{co}$ en el siglo XV y ello se tradujo en un intenso tráfico en el comercio artístico. No cabe duda de que fue una de las sedes principales en la que se desarrolló el paradigma del Renacimiento habsbúrgico de las artes, al decir del profesor Fernando Checa².

Esta expresión de la magnificencia en el ejercicio de las artes continuó durante el período Barroco, donde gracias a una infanta proveniente de la corte de un príncipe del Renacimiento, Isabel Clara-Eugenia, los Países Bajos Meridionales desarrollaron una Edad de Oro cuya máxima expresión artística puede identificarse con las creaciones de Rubens ${ }^{3}$. Así, podemos decir que en el contexto del Siglo de Oro existió una importante economía basada en el comercio artístico. Es aquí donde situamos la figura del pintor Teniers II, pues en la segunda mitad del seiscientos su taller lideró esa red económica artística brabantina.

1. Sobre la corte de Bruselas y la restauración de la casa de Habsburgo en Flandes véase Werner, 2000.

2. Checa Cremades, 2017.

3. Vergara, 2000. 
Este ensayo no pretende profundizar tanto en las cuestiones relativas a la percepción que su pintura generó entre sus contemporáneos en términos de retórica plástica, es decir, de los efectos visuales de su técnica pictórica, sino en el concepto de recepción, más basado en perspectivas económicas y sociales. Por ello, la herramienta teórica y crítica sobre la que se apoya este trabajo se centra en exponer los datos relativos al liderazgo de la obra de Teniers en la red económica artística del Siglo de Oro. Por ello revisamos las fuentes ya publicadas, pues hay datos que necesitan de una relectura en su contexto.

Además, en los fondos documentales de las notarías generales de Brabante, dentro de los Archivos del Estado de Bruselas, se han localizado documentos inéditos que permiten adentrarnos en el funcionamiento del taller de Teniers II y acercarnos a aspectos de coleccionismo artístico hasta ahora poco tratados, como sus clientes, pues se sentían atraídos por la rareza y curiosidad de su paleta y llegaban a su domicilio para «veoir la rareté des peintures».

\section{BREVES NOTAS SOBRE EL PINTOR DAVID TENIERS II}

En 1777 Antonio Ponz 4 dedicaba unas palabras a los Teniers que decoraban los gabinetes del Palacio Real de Madrid, donde ahora lucían procedentes del palacio del Buen Retiro ${ }^{5}$. A juzgar por su tono, el historiador ilustrado parecía querer mostrar poco aprecio por unas obras a las que definía de «bambochada» o «asuntos ridículos que (Teniers) habitualmente pintaba» y de las que no ofrecía ninguna descripción ${ }^{6}$. Sin embargo, en esa época, la pintura de Teniers no sólo gozaba ya de alta estima 7 , sino que llegó a alcanzar cifras muy elevadas ${ }^{8}$. Por ello, más que un discurso negativo, la mirada culta de Ponz quiso definir de forma genérica esas escenas moralizantes que ridiculizaban los placeres sensuales del hombre y que tanto interés alcanzaron en la pintura de Teniers, siguiendo la tradición que se había iniciado en el Flandes del siglo XVI.

\footnotetext{
4. Antonio Ponz Piquer (1725-1792) destacó por tener una amplia formación cultural que le llevó a ser una figura esencial en el contexto de la política ilustrada de los Borbones. Fue importante su trabajo al frente de la recopilación de obras y reliquias de la Biblioteca del Escorial, donde completó su galería de retratos y copió cuadros de algunos maestros italianos. Sus ideas se apoyaron sobre las bases de dar a conocer y proteger el patrimonio artístico nacional. Su obra el Viaje de España, publicada en dieciocho volúmenes entre 1772 y 1794, ha sido considerada como un intento de inventario exhaustivo de lo que aún no era llamado como patrimonio artístico español. Sobre este asunto véase Frank, 1997.

5. García-Frías, 2015

6. Ponz, 1772-1794, párrafo 37.

7. En 1778 el príncipe Carlos, futuro Carlos IV, llegó a pagar 1850 reales de vellón por una «pintura del Diluvio» que se colocó en la casita de campo de San Lorenzo de El Escorial. El dato fue publicado por Urriagli Serrano, 2012, p. 49.

8. Estas cifras se justifican por la fama y cotización que alcanzó su obra, lo que hizo posible que su pintura estuviera entre las colecciones de los primeros Borbones en España, especialmente en la de Isabel de Farnesio, y que se copiara en los tapices que adornaron los reales Sitios de Madrid. Para ello, Aterido Fernández et al., 2004 y Herrero Carretero, 2000.
} 
David Teniers el Joven (1610-1690) fue quizá el artista flamenco más activo de la generación que sucedió a Pieter Paul Rubens (1577-1640) y no exageramos al afirmar que llegó a ser el gran pintor de género del siglo XVII ${ }^{9}$ [Fig. 1]. Nacido en Amberes en 1610, se había instalado en Bruselas en 1650, y un año después fue nombrado pintor de cámara del archiduque Leopoldo Guillermo, en sustitución de Van den Hoeck. En 1656, tras la marcha del archiduque a Viena, siguió en el mismo cargo con don Juan José de Austria ${ }^{10}$. Aunque se ha señalado que tras la salida de este último sus ambiciones pudieron verse frustradas, Teniers continuó siendo beneficiario del mecenazgo de los gobernantes de Flandes, como Luis de Benavides, marqués de Frómista y Caracena, aun cuando en el caso ya eran gentilhombres y no príncipes de sangre ${ }^{11}$. Incluso, recientemente, nueva documentación demuestra su labor como conservador y restaurador de la colección real de Bruselas, entre Tervueren y Coudenbeg ${ }^{12}$.

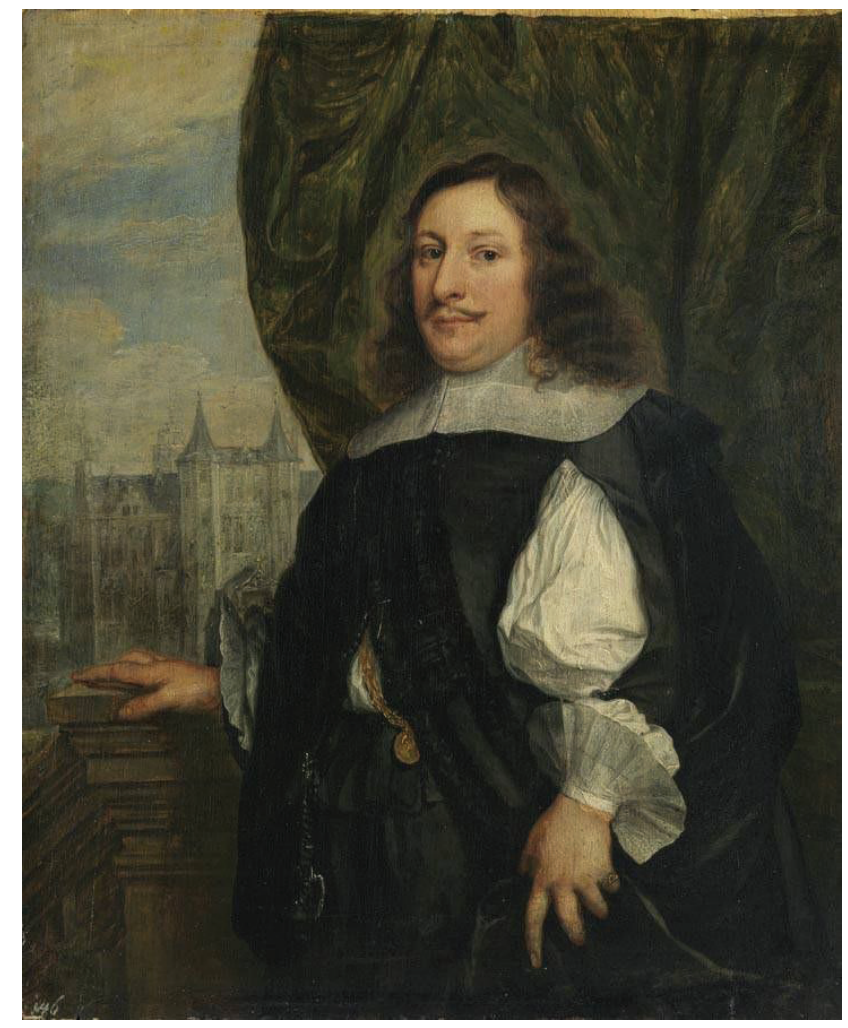

Fig. 1. Retrato de David Teniers, el Joven, Pieter Thijs, 1659. Staatsgalerie im Neuen Schloss, Schleissheim

9. La bibliografía esencial del pintor: Rosenberg, 1895; Peyre, 1910; Bocquet, 1924; Davidson, 1979; Klinge, 1982 y 1991; Díaz Padrón y Royo-Villanova, 1992; Klinge y Lüdke, 2005 y Vlieghe, 2011.

10. González Asenjo, 2005.

11. Moreno García, 1980.

12. Romero y Van Belle, en prensa. 


\section{LA PRODUCCIÓN DE TENIERS II Y SU TALLER}

La producción de Teniers basculó entre temas alegóricos y bíblicos, vistas de los famosos gabinetes de pinturas, paisajes y retratos, dando muestra incluso de sus habilidades como copista de pintura italiana ${ }^{13}$. Dotado de una técnica virtuosa y de efectos sugerentes, con una paleta cromática muy sutil y delicada, tuvo una exitosa carrera artística. El volumen de encargos que recibió fue tan elevado que su taller contó con un buen número de colaboradores, entre los que se encontraban los miembros de su familia: sus hermanos Theodore (1619-1697) y Julen II (16161679?) y sobre todo Abraham Teniers (1629-1676?), junto a su hijo David Teniers III (1638-1685). Resulta paradójico que tan solo se conozcan los nombres de tres de sus discípulos, Matheus Milese (1640-1641), Gilles van Bolder (1643-1644) y Jan de Froey (1647-1648), de los que, a su vez, se ignora su obra como artistas independientes ${ }^{14}$.

Los datos que conocemos del mercado artístico flamenco en la segunda mitad del siglo XVII, cuando la producción de Teniers fue meteórica, son bastantes más escasos que los del período del gran Rubens. Hay que tener en cuenta que tras la era de los archiduques Alberto e Isabel ${ }^{15}$, los Países Bajos españoles experimentan una crisis política y militar que pudo mermar el rico comercio artístico de pintura en Flandes.

Esta crisis no parece que afectara a Teniers, quien tuvo un ritmo frenético de trabajo. De sobra es sabido que el pintor contó con el mecenazgo de los miembros de la dinastía de los Habsburgo ${ }^{16}$, especialmente de Felipe IV ${ }^{17}$, que no sólo tuvo desde muy temprano sus obras ${ }^{18}$, sino que le apoyó en su proyecto de crear la Academia de Amberes, inaugurada en 1663. Gozó además de la admiración de Cristina de Suecia, Guillermo II de Orange, el duque de York o Luis II Condé.

El taller de Teniers comercializó sus obras de diversas maneras, ya fuese enviando estas a clientes potenciales, organizando subastas en su propia casa o mediante agentes de arte. A pesar de ello, hasta el momento no poseíamos datos que

13. Ello se evidencia en las pequeñas reproducciones de las pinturas italianas de la colección de Leopoldo Guillermo que le sirvieron como modelo para los grabados del Theatrum Pictorium, a modo de gran catálogo monumental de la colección del archiduque. La primera edición fue publicada en Bruselas en 1660, bajo la dirección de Abraham Teniers e impresa por Hendrick Aertssens, con un contenido de 229 estampas. En 1684 fue publicada la segunda edición realizada por Jacob Peeters con 243 estampas. Ver al respecto Klinge, 2003.

14. Davidson, 1979, pp. 55-63.

15. Vergara, 2000.

16. Como el archiduque Leopoldo Guillermo de Austria o don Juan de Austria, con quien Pedro de Madrazo relaciona el incremento de pinturas en la colección real a fines del siglo XVII, hipótesis que no cuenta con respaldo documental. Sobre ello Madrazo, 1884, pp. 141-145.

17. Los reyes mostraron cierto interés por el tipo de pintura de gabinete realizado por Teniers, particularmente los dos últimos Austrias, Felipe IV y Carlos II, pero también los Borbones. Ello explica las diez pinturas originales de Teniers que conserva Patrimonio Real. Este asunto en García-Frías, 2015.

18. El inventario del alcázar de Madrid realizado a su muerte en 1666, recoge hasta ocho obras originales del pintor. Sobre este asunto Martínez Leiva y Rodríguez Rebollo, 2015. 
nos informaran de manera directa sobre el funcionamiento del obrador de Teniers. Como en seguida veremos, los documentos inéditos conservados en la notaría general de Brabante confirman el importante volumen de trabajo que experimentó el atelier de Teniers en la década de 1660. Pero antes de entrar en este asunto, hay que abordar una cuestión que nos permitirá contextualizar la posterior situación que vivió Teniers.

\section{LAS ASPIRACIONES SOCIALES DE TENIERS II}

Se ha señalado la destacada posición social de la que gozó el artista debido a su condición de pintor y ayuda de cámara de Su Alteza. Teniers amasó una considerable fortuna en propiedades inmobiliarias ${ }^{19}$. El 13 de octubre de 1656 adquirió un terreno en las inmediaciones del Hôtel Ravenstein de Bruselas, es decir, en la Rue Terarcken, justo al lado del palacio de Coudenberg ${ }^{20}$. En un mapa de 1695 publicado por J. Laboureur y J. Vander Baren en «Bruxella nobilissima Brabantiae civitas» las casas de Teniers se localizan en el ángulo de la Jodentrappen y de la Rue Isabelle, justo detrás de la maison Ravenstein [Fig. 2].

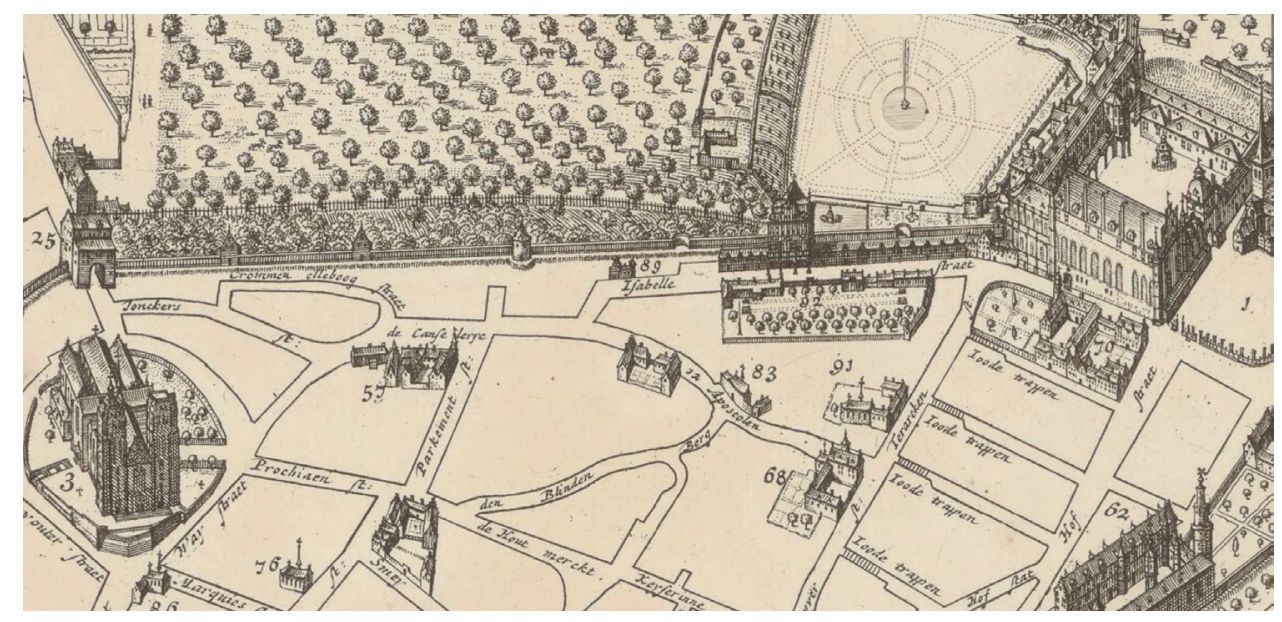

Fig. 2. Casa de Teniers en Bruselas. J. Laboureur y J. Vander Baren [1695] en «Bruxella nobilissima Brabantiae civitas»

Teniers tuvo grandes aspiraciones sociales y ansiaba su ennoblecimiento, pero no parece que quisiera obtenerlo a condición de renunciar a su oficio. Así, se conoce la patente de nobleza que había solicitado para él y sus descendientes, el 7 de enero de 1655, en la que adjuntaba un elaborado escudo de armas ${ }^{21}$. Siguiendo los datos publicados por Pinchart, el archivista Vermoelen señalaba que el 16 de enero de 1657 Teniers había elevado una petición al Consejo de Amberes en la

19. Dreher, 1978, p. 683.

20. Des Marez, 1912, pp. 44-45.

21. Pinchart, 1860, p. 53. 
que pedía hacer uso de su escudo de armas. El Concejo pareció acceder bajo una estricta condición «qu'il ne luy sera permis d'exercer l'art de sa dicte profession publiquement pour aucun gain ou sallaire, aynsy que sont accoustumez de faire ceux de ceste condition, à paine d'estre tenu pour desceu d'icelle grâce» ${ }^{22}$. Dicho de otro modo, el Consejo antuerpiense le prohibía ejercer su oficio de pintor de manera pública, es decir, exponer su producción en casa y destinar su pintura a la venta pública.

Aunque sabemos que no fue hasta 1680 cuando Teniers recibió la confirmación real para hacer uso del escudo de armas familiar, parece que de cara a las autoridades locales asumió la condición impuesta, pero, por detrás, eludió la ley. Además, todo apunta a que esta prohibición no tuvo trascendencia más allá del ámbito local. De hecho, como enseguida veremos, importantes personalidades acudían a su domicilio «sous la croyance qu'il avoit qu'on les devoit vendre publicquement et au baston» ${ }^{23}$, es decir, para participar en la venta pública de pintura. Sin embargo, una vez allí, recibían la noticia de que la tal venta se había prohibido «en raison de quelque interdiction (tal y como se declara) $»^{24}$ sin que se especificasen los motivos. ¿Por qué se le prohibía vender en subasta pública?

La fama de Teniers y su ambición personal no tuvieron límite y el solo rumor de venta pública en su casa era motivo para que los clientes y mecenas se desplazaran interesados por «veoir la rareté des peintures» ${ }^{25}$. Como tendremos ocasión de demostrar, las pinturas de Teniers se movían dentro de un sistema de convenciones simbólicas ${ }^{26}$ llenas de interpretaciones iconográficas muy personales que atraían sobremanera a los clientes, por ser consideradas como raras. Sin duda, su retórica visual era percibida en la época como sobresaliente, extravagante y única en su género.

\section{EL GREMIO DE PINTORES DE BRUSELAS Y LOS CLIENTES DE TENIERS II}

Habitualmente la pintura de género solía realizarse de forma libre, sin la petición de un cliente previo, y por ello necesitaba ser expuesta en público para su venta. Tal y como comenta Palomino, el primer Arellano «tuvo obrador público de pintura cer-

22. Vermoelen, 1870, p. 4. Incluimos una traducción al castellano actual de esta cita textual: 'No se le permitiría ejercer su oficio de pintor de forma pública, es decir, como un profesional que recibía un salario por sus creaciones, y de hacerlo le sería retirado el uso de su escudo de armas'.

23. Archives de l'Etat Bruxelles (AEB). Forest, Notariat Général de Brabant (NGB), núm. 2574/1. Incluimos una traducción al castellano actual de esta cita textual: 'Confiando en que podían comprar la pintura en subasta pública'. El bastón era el instrumento que se utilizaba para el remate del precio tras la puja. 24. El testimonio de don Carlo Pucy, de 14 de diciembre de 1666, no recoge el motivo, pues este no se especificaba para evitar su trascendencia a mayores. AEB. Forest, NGB, núm. 2574/1.

25. AEB. Forest, NGB, núm. 2574/1.

26. Algunos historiadores del arte han señalado la potencialidad metafórica y la función narrativa de las acciones, animales y objetos en los cuadros del pintor y que han relacionado con la biografía del pintor. Así, Arias Bonel (2005) relaciona la obra El concierto interrumpido con la misión de cobijar la denuncia de una afrenta. 
ca de cuarenta años y fue una de las más célebres tiendas que hubo en la Corte» ${ }^{27}$. Por tanto, era habitual en el contexto de la Europa burguesa la venta de obras de arte en tiendas. Además de trabajar para un cliente, el artista podía pintar lienzos que dejaba en su obrador como «en stock» para la venta al público.

En el contexto de la ciudad de Bruselas la venta pública de obras de arte era un tanto particular. Al parecer, el gremio de pintores gozaba de un privilegio que la ciudad le había otorgado en 1559 y ratificado en 1647 y en cuyos artículos núm. 30 y núm. 31 se prohibía a estos poder vender su trabajo en subasta pública, salvo en las dos ferias anuales o en el caso de tratarse de obras procedentes de defunciones, marcha de la ciudad o quiebra del negocio. De hecho, el 19 de noviembre de 1666, los decanos del gremio presentaron una petición al Soberano Consejo de Brabante para que esto se hiciera cumplir28. ¿Qué motivó esta petición?

No parece que Teniers tuviera buena sintonía con sus compañeros de Bruselas y con el gremio, entre otras cosas porque su condición de pintor de Corte le eximía de registrarse como miembro del mismo. No cabe la menor duda que la fama del pintor había generado envidias entre sus compañeros. Sabemos que el gremio de Bruselas tomó acciones legales contra él en dos ocasiones, en 1666 y en 1683.

El 9 de diciembre de 1666, el pintor paisajista Ignatius van der Stock ${ }^{29}$ testificaba, por orden de los decanos del oficio de pintores, batidores de oro y vidrieros de Bruselas, ante el notario A. Vanden Kerckhove, que el viernes 3 de diciembre antes del mediodía había acudido al domicilio de Teniers, situado en Jodentrappen, y que había visto una multitud en su salón que había venido para ver o comprar sus obras. El declarante vio cómo Teniers subastó su pintura y afirmó que él mismo compró dos de ellas acordando abonarlas en un período de tres meses, algo que quedó recogido ante el notario Vanden Driessche ${ }^{30}$. Después, afirmó que Teniers, no contento con los precios propuestos, retiró sus obras de la subasta. Como pasaremos a detallar, la venta se llevó a cabo de forma privada argumentando cierta prohibición.

El documento que dio a conocer De Marez evidencia que la subasta en casa de Teniers se llevó a cabo quince días después de que el gremio hubiese hecho valer su privilegio ante el Soberano Consejo de Brabante. Hay que tener en cuenta que

27. Martín González, 1984, p. 177. Se tiene noticia de que Juan de Arellano (1614-1676), fundamentalmente especializado en los cuadros de flores, colabora con otros artistas que realizaban las figuras que él rodeaba con sus composiciones florales, tales como Francisco Camilo y Mateo Cerezo. Su hijo, José de Arellano, repitió como discípulo los modelos de su padre. También su yerno, Bartolomé Pérez de la Dehesa. 28. Galesloot, 1868, pp. 264-265.

29. Ignatius Van der Stock (1635-después de 1665) fue un pintor y grabador flamenco especializado en la pintura de paisajes y fue maestro de algunos paisajistas de renombre como Adrián Frans Boudewijns. Sobre él véase Díaz Padrón, 1995, p. 1317 y Callatay, 1960.

30. Archives Générales du Royaume (AGR). Notariat. Minutes du notaire A. Vanden Kerckhove, liasse 1698. El documento fue editado por De Marez, 1912, pp. 47-48. Hemos consultado el original al observar que la cita de Vlieghe contenía errores en la fecha, al señalar que la subasta se había llevado a cabo el 6 de diciembre, cuando el documento deja claro que se celebró el 3. Al respecto Vlieghe, 2011, p. 94. 
una subasta pública debía de anunciarse con cierta antelación, sobre todo para que los clientes pudieran organizarse ¿Fue su anuncio lo que motivó la petición del gremio?

Hemos de tener en cuenta que a ella acudió como testigo, obviamente enviado por el gremio, el pintor Van der Stock y su testimonio iba a ser tomado como base para denunciar a Teniers. En cualquier caso, el fallo se hizo esperar, y no llegó hasta 12 de mayo de 1670. En su veredicto señalaba que el gremio no había tenido en cuenta la ordenanza local de 1 de junio de 1664, en la que se especificaba que cualquier burgués tenía derecho a vender sus pinturas en público siempre que estas fuesen de una sola autoría, es decir, no estuviesen firmadas por otros maestros. La denuncia contra Teniers fue desestimada y el gremio de Bruselas fue acusado de mala fe obligando a pagar al maestro las tres cuartas partes de sus honorarios en la Corte ${ }^{31}$.

Todo apunta a que, efectivamente, Teniers estaba muy bien asesorado y el testimonio de Ignatius van der Stock, en el que afirma que el pintor suspendió la subasta pública, no se debió a la prohibición del gremio, pues esperó a que se celebrara para denunciarlo, sino a sus intereses económicos. El maestro utilizó el mecanismo de la venta privada para obtener un mayor beneficio. Un documento inédito nos permite conocer que así se celebró ese mismo día y en ella participaron los siguientes clientes 32 :

1. El príncipe Fernando Alejandro de Portugal, marqués de Trancoso y conde de Sandim

2. Don Carlo Puci, caballero de la Orden de Cristo, capitán de caballería

3. Antoine Roelofs, señor de Géronpont

4. Pierre Ignace Vendeville

5. Guillaume Sadeler «Tensier» (?) de S. M.

6. Guillaume Sterck «oproeper» de la villa de Bruselas

7. François van Outers «oproeper» de la villa de Bruselas

8. Henri Cruykens, antiguo decano de los «Witwerkers» (ebanistas de madera blanca)

9. Philippe Cordonnier, empleado de la Audiencia General

10. Don Juan de Vano de Velasco, consejero superintendente de la Cámara de Cuentas de Gueldre

11. Jean Ignace Weyns, abogado

12. Balthazar de Robiano, señor de Steenvoorde, que vino para «veoir la rareté de ses peinctures»

Reunidos los potenciales clientes, Teniers, con el fin de evitar cualquier contratiempo que le comprometiese, les invitaba a declarar bajo notario que dicha venta se iba a realizar bajo contrato de común acuerdo «sans obtenir les solennitez du 
coup de baston ny cry publicq» ${ }^{33}$, es decir, sin seguir el procedimiento público con arreglo a la ley. Dos de los sujetos que participaron en dicha venta, es decir, el príncipe Fernando Alejandro de Portugal y el empleado de la Audiencia General, Philippe Cordonnier, dan un testimonio tan preciso y precioso que nos permite conocer al detalle cómo se desarrolló la misma.

El testimonio del príncipe Fernando Alejandro de Portugal deja claro que él aceptaba la venta y que esta no se realizaba con la solemnidad pública acostumbrada, sino de mano a mano. Es significativa su declaración por cuanto señala que su presencia allí se debe a la intención de comprar pintura «de su gusto» y que reconoce a muchos de los comerciantes de Amberes que acuden con esta misma intención. Como luego veremos, el príncipe de Portugal era un gran entendido en arte y se desplazaba en busca de ricas obras para satisfacer sus deseos. Citamos el testimonio in extenso por ser de una gran calidad expositiva:

Cejourdhuy le 14 de décembre l'an de grace mil six cent soixante six pardevant moy notaire et tesmoins embas denommez comparut en sa personne son Excele seigneur Prince Don Ferdinande Alexandre de Portugal, marquis de Trancoso, comte de Sinde, des consauls de Portugal de sa Mate etc lequel a dit et déclré comme il déclare et atteste par cette de s'estre trouvé personnellement le troisièsme de ce présent mois après midy au logis du Sr David Teniers, peintre et ayude de chambre des Sermes Archiducq Léopolde et Don Juan d'Austriche pour y faire acheter quelques peinctures à son goust soubs la croyance qu'il avoit qu'on les devoit vendre publicquement et au baston, mais estant arrivé au logis dudt Sr Teniers, il trouva que les dictes peintures n'estoyent pas à vendre en la manière susdite a raison de quelque empeschement ou interdiction et ainsy comme ledt seigneur prince comp(aran)t souhaitait grandement d'avoir quelques peinctures il fit instance vers ledt $\mathrm{Sr}$ Teniers de luy en vendre quelques unes hors la main, comme à la fin il le fist, et de mesme à quelques autres personnes quy se trouvaient là présent pour en achapter et notament a quelques marchands d'Anvers que ledt seigneur Prince declare cognaistre et estoy venu en cestte ville a cest effet déclarait aussi bien expresement que toutes les peintures ont esté vendues audit Seigneur Prince et aux autres en sa présence hors la main et sans aucun cry publicq ny coup de baston, ce que ledit Segn Prince comparant en faveur de la justice et de la vérité afirmera et attestera toties et quoties. Ce qui fut ainsy fait et passé à Bruxelles à la réquisition dudict Sr. David Teniers en présence de Jean Phlippe de Rijcke et Jean Formanoir (?) bourgeois de cette ville come tesmoins ${ }^{34}$.

33. AEB. Forest, NGB, núm. 2574/1 Testimonio de J. I. Weyns. 'Sin la solemnidad del golpe de bastón ni el grito público'.

34. AEB. Forest, NGB, núm. 2574/1. Hacemos una glosa de la cita del texto en francés para que resulte más comprensible al lector: 'Hoy 14 de diciembre del año de la gracia de mil seiscientos y sesenta y seis ante la presencia del notario y de los testigos mencionados compareció en persona el excelente lord y príncipe don Fernando Alejandro de Portugal, marques de Trancoso y conde de Sandim, del consulado de Portugal de su Majestad. Así compareció y dijo que él había estado el día tres de este mes de la data en la casa del señor David Teniers, pintor y ayuda de Cámara de los Serenísimos señores el archiduque Leopoldo Guillermo y don Juan José de Austria, para comprar pintura de su gusto creyendo que las podía adquirir en venta de subasta pública. Sin embargo, al llegar a su taller le fue notificado que estas no se podían adquirir bajo este procedimiento por ciertos impedimentos y prohibiciones. Como el príncipe deseaba tener pintura de Teniers este la adquirió de forma privada de la mano de Teniers, al igual que 
Más vivo y expresivo resulta el testimonio de Philippe Cordonnier, empleado de la Audiencia General. En su declaración afirma que vino a casa del maestro para «veoir la rareté des peintures dudict Sr Teniers», es decir, atraído por su estilo de pintura. Allí permaneció para ver cómo se hacía la venta. El texto notarial deja claro que Teniers se dirige a los clientes en neerlandés, si bien el escribano lo refleja en un precioso francés medio, con expresiones tales como «Neny Monsieur», es decir, '¡No, no, Señor!'. El testimonio refleja que Teniers trajo pinturas de la planta baja, es decir, del lugar dónde se situaba el taller, para que fuesen admiradas en su salón. Recordemos que el obrador se ubicaba casi siempre en la planta baja, pues generaba ruidos y además eran necesarios espacios para almacenar los materiales y, a veces, trabajar sobre una superficie firme y segura.

El testimonio refleja cómo varios de los clientes allí congregados pujan por las pinturas, incluso alguien a voz en grito quiso dar un florín más, pero Teniers les interpela señalando que no es una venta pública y que, por tanto, ni hay regateo a viva voz ni solemnidad de bastón. El texto señala que él lo hace fuera de toda solemnidad «hors la main» y conocemos las expresiones de ofrecimiento de Teniers invitando a sus clientes a comprar la pintura, Prennez-la, como queriéndole señalar que se la vendía por el precio pactado, pero sin puja. Sin duda, también este texto merece ser citado in extenso:

[...] veoir la rareté des peintures dudict Sr Teniers et y entrant luy demandant «et bien Monsieur Teniers faict on icy vendition des peintures» a quoy ledt $\mathrm{Sr} \mathrm{Te}$ niers répondit audit Sr comparant [en langue flamande] Neny Monsieur on m'en a faict interdiction, mais je vend mes peintures hors la main, ce qui m'est permict de faire comme à un chacun et ce enseignant le Compt s'est arresté pour veoir ce qui s'y passoit ou se passeroit et at veu ledict S[eigneur] comparant q[ue] ledict Sr Teniers vendoit quelques peinctures qu'il faisait apporter dans sa salette d'embas, et qu'après qu'ils avoient esté veues et considérées par quelques amateurs qui estoient la présent, quelques uns d'iceux firent offre de quelque prix pour icelles, le Sr Teniers leur répondoit Prennez la, et quelques fois, disoit je ne la peut donner pour ce prix et l'on faisant quelque offre plus grand, ledict Sr Teniers dit Prennez la, comme voulant dire qu'il luy vendoit ladicte peinture pour le prix qu'il en avoit offert ayant aussy remarqué que quoy qu'un aultre en vouloit donner quelque chose de plus (et ce une fois ou deux) ledt S. Teniers faisoit suyvre(?) la peincture a quy il luy plaisoit adjoustant ledt $\mathrm{Sr}$ comparant que ledt jour troisiesme dudit mois avant midy, ayant vu personne de l'assemblée cryé tout hault qu'il donneroit un florin ou plus sur la pièce exposée ledt Sr Teniers répondit à pleine voix: Hola Messieurs, on ne faict poinct vende, mais je vend mes pièces hors la main, et de faict il n'y avoit point de cryeur, ni aultre personne avecq le baston comme il se practique en vendes publiques pour publier le prix de la chose exposée... ${ }^{35}$.

otros clientes allí congregados; especialmente unos comerciantes de la ciudad de Amberes que don Fernando Alejandro aseguró conocer. Así reconoció que toda la pintura fue comprada de forma privada, de mano a mano, sin el regateo a voces de la venta pública y el remate del precio con el bastón. De ello el príncipe Fernando Alejandro dio fe y testimonio, en Bruselas, a petición de Teniers y en presencia de los testigos Jean Phlippe de Rijcke y Jean Formanoir (?) burgueses de esta ciudad'.

35. AEB. Forest, NGB, núm. 2574/1. Hacemos una breve glosa de la cita del texto en francés para que resulte más comprensible al lector: ' ... para ver la rareza de las pinturas del dicho Teniers y al entrar en su 
Muchos de los clientes allí congregados expresan la noción de rareté con la que se refieren a las obras de Teniers, un poco como si la producción del pintor hubiese sido más escasa ese año de 1666. Hemos de señalar que meses más tarde, es decir, en mayo de 1667, iba a estar muy ocupado con las colecciones reales del castillo de Tervueren. ¿Qué causas pueden explicar una cierta ralentización en la producción de su taller? ¿Tuvo acaso problemas de salud?

Un testimonio inédito de fecha de 4 de marzo de 1667 nos pone sobre la pista. Un tal Egidius Michiels, burgués habitante de Bruselas de 31 años de edad, en calidad de marchante de pintura, testifica ante notario que desde hacía siete años venía suministrando al taller del maestro una gran cantidad de tablas de madera, lienzos, pinturas, pinceles y otras cosas que eran necesarias para el oficio. Si bien, esta venta se había visto muy disminuida después de que su taller no contara con trabajadores, como afirmaba textualmente: «tseders de voorschreven herre requirant [D. Teniers] geene knechten meer en is houdende, syne leveringe geheel gemmidert is ${ }^{36}$. ¿Por qué no contaba con trabajadores?

Por razones que se nos escapan, el taller de Teniers vio aminorada su producción. Sin embargo, varios registros notariales de la misma fecha que la venta privada de 1666, por tanto, tres meses antes del testimonio del marchante belga que venimos de citar, permiten relativizar esta cuestión. Así, Jan Roos, burgués de Bruselas y escultor de 25 años de edad, declaraba haber entregado al taller de Teniers el año pasado, es decir, en 1665, una cantidad importante de marcos, «masse de cadres», para servir a las pinturas del maestro. Del mismo modo, Jan Courtois, burgués de Bruselas y batidor de oro, afirmaba haber batido oro desde hacía más de doce años para dorar los marcos de las pinturas de Teniers. En la misma línea, el testimonio de Hendrick Cruyckens, burgués de Bruselas y maestro ebanista en madera blanca, que declaraba haber servido, desde principios de 1666 hasta la fecha del testimonio notarial ( 3 de diciembre), al taller de Teniers con una gran cantidad de marcos para que los escultores del taller los adaptaran al formato de las pinturas ${ }^{37}$.

Sin duda, los testimonios de J. Roos y de $\mathrm{H}$. Cruyckens indican que la actividad del taller no bajaba la guardia en vista de los encargos que recibía y, por tanto, la declaración de Egidus Michiels debe ser entendida como una situación pasajera. En estos momentos, al solo rumor de una venta de pinturas de Teniers los compradores acudían raudos a su domicilio, persuadidos por su fama y reputación.

taller le dijo: «Señor Teniers, procedamos a la venta de sus pinturas», a lo que él le respondió, en flamenco: «iNo, no! yo vendo mis pinturas de mano a mano, por tener prohibida la venta en subasta pública». Teniers trajo pinturas de la sala baja, donde estaba su taller, y algunos amateurs que estaban presentes le hicieron una oferta para adquirirlas. Teniers dijo: «iTómalo!» e incluso manifestó que no podía venderlo por ese precio... Teniers dijo: «Yo vendo mis pinturas de forma inmediata, de mano a mano». De hecho no hubo grito, ni persona con el bastón como se practica en las ventas públicas para dar salida a la obra que se pretende vender...'. 


\section{UN CLIENTE DESTACADO: DON FERNANDO ALEJANDRO DE PORTUGAL}

No cabe duda de que la pintura de Teniers causó un gran impacto en la cultura visual de su tiempo, en especial en la Europa Barroca y en el contexto de los Países Bajos españoles. Su retórica visual tendía a mostrar los excesos de una sociedad, mediante la alegoría y la sátira, con un claro fin moralizante. Además, es un gran testimonio para conocer la cultura material de la época, por cuanto nos proporciona una valiosa información de la vida cotidiana.

¿Qué veían en ella personajes como el príncipe Fernando Alejandro de Portugal? ¿Por qué era este género de pintura, tal y como manifiesta el notario, conforme a su gusto? El príncipe Fernando Alejandro de Portugal era hijo de la dama napolitana Anna Capece, cuyo padre era el marqués de Monleone, y de Luis Guillermo de Portugal. Aunque su hermano Manuel fue el primogénito de este matrimonio, por hacer carrera eclesiástica había renunciado en Fernando Alejandro a los títulos y rentas cuando falleció su padre en Madrid en 1660. Aunque estos príncipes eran Portugal y Nassau-Sajonia, siempre quisieron ser llamados Príncipes de Portugal con la intención de mantener vivas sus aspiraciones al trono portugués hasta finales de la década de $1630^{38}$.

Don Fernando Alejandro de Portugal fue definido por Diego Duarte de Amberes, mercader de origen lusosefardí y cliente de Jan Vermeer, como «le grand curieux» ${ }^{39}$ $y$, efectivamente, la visita al taller de Teniers permite corroborar este extremo. Conocemos su colección pictórica gracias al anuncio de la subasta impresa en Bruselas en 1670. El impreso contenía los nombres de los autores y los títulos de las pinturas, así como en ocasiones su soporte y formato ${ }^{40}$. Sabemos que otras piezas de su colección fueron vendidas en subasta pública en marzo de 1670. Se trató de una venta almoneda de las pinturas que había llevado a la corte o reunido allí. La tasación fue realizada por Antonio de Pereda el 9 de abril de 1669 y, entre otras obras, se vendieron dos «bambochos» originales de David Teniers [«Esternis»], un frutero y «un cuadro aovado con su marco de escoltura dorado representando a nuestra señora con el niño Jesús, San Josef y San Juanico» vendido «en cincuenta ducados» a Fernando Vergara ${ }^{41}$.

El documento de la almoneda del príncipe Fernando Alejandro de Portugal tiene un gran valor por cuanto nos corrobora que las pinturas que había comprado en la subasta privada de Teniers, el 3 de diciembre de 1666, eran de género «bambochos» y que este era de su gusto, intención que fue la que motivó la visita al taller de Teniers. En realidad, este concepto se empleaba para referirse a los cuadros de género y procedía del italiano «bamboccianti» por la forma en la que se denominaba

38. Por línea paterna descendían del Prior do Crato y de Guillermo de Orange, pues Emilia de Nassau, hija del Taciturno y de Ana de Sajonia, se había casado en 1597 con Manuel de Portugal, hijo y heredero de D. Antonio de Portugal. Véase Kamp, 1980.

39. Denucé, 1949

40. Bouza, 2017.

41. Bouza, 2017, p. 41 
de manera peyorativa al grupo de pintores en torno a Pieter van Laer (1599-1642), apodado «il Bamboccio» ${ }^{42}$.

Como vemos, este género de pintura causó una gran sensación en el contexto de la Europa Barroca, al tratarse de escenas de la vida cotidiana, interiores domésticos o tabernas, en la que habitualmente individuos de clases populares fumaban, bebían, pelean o se mostraban sin disimulo [Fig. 3]. Los aspectos de la vida cotidiana fueron los objetivos de la complacencia de Teniers, ambientes que habían sido considerados anteriormente como indignos para un artista de su rango. De hecho, tanto Pacheco como Carducho habían afilado su pluma para definirla como pintura vulgar. No fueron de la misma opinión los ciudadanos flamencos a los que gustaba verse reflejados en actos y vida de las gentes humildes con gran riqueza de color y explosión de una alegre poética. Curiosos y amateurs acudían a la casa de Teniers para hacerse con las mejores pinturas de este género.

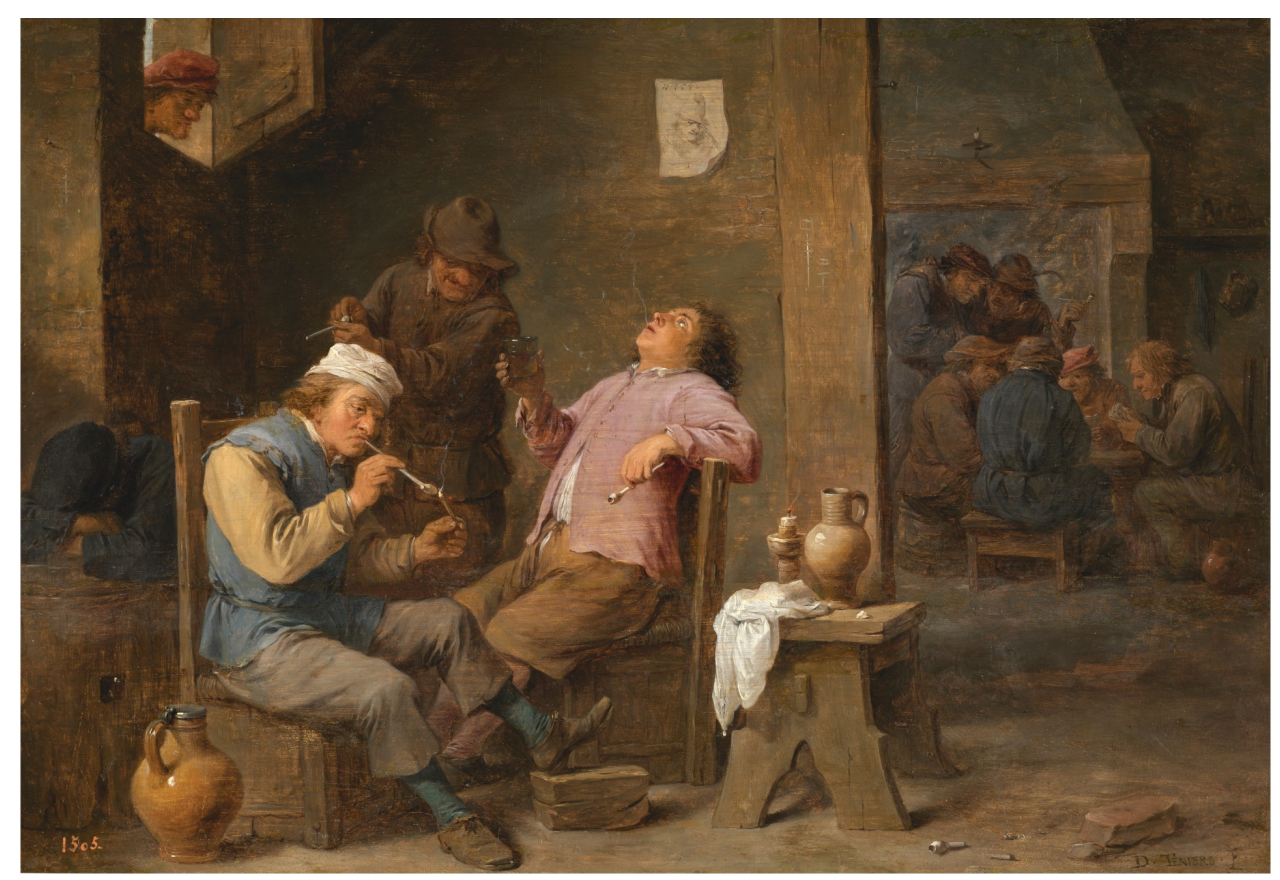

Fig. 3. Fumadores y bebedores, David Teniers, II, óleo sobre tabla, 34 × 48 cm, 1652. Museo Nacional del Prado [P001794]

\section{DE VUELTAS CON EL GREMIO DE PINTORES DE BRUSELAS}

Como ya hemos señalado, aunque Teniers había ganado la partida al gremio este no se dio por vencido y volvió a la carga en 1683. Este año Teniers anunció una nueva subasta pública y en esta ocasión la repercusión tuvo un gran eco en el 
extranjero. El día fijado era el 19 de julio donde subastaría en casa muchas pinturas hermosas y raras, italianas, holandesas de varios maestros, así como obras de su mano, tanto originales como copias o algunas copias retocadas. En esta subasta se incluía una gran Crucifixión de Tintoretto ${ }^{43}$.

Ante estas circunstancias, el gremio de Bruselas no solo mandó retirar los carteles que la anunciaban, sino que acudió al Consejo Soberano de Brabante por ver vulnerados sus derechos ${ }^{44}$. En esta ocasión, además de apelar a los artículos 30 y 31 del privilegio de 1559, ratificado en 1647, señalaron que Teniers no se podía amparar en la ordenanza local de 1 de junio de 1664, puesto que la magistratura de Bruselas la había declarado nula, pues había sido emitida por el entonces decano Gillis Van Tilborch sin ninguna consulta interna. El gremio incluso sostuvo que Teniers se valía de excusas como problemas financieros derivados del reparto de la herencia entre los hijos de su primera esposa o una supuesta marcha de la ciudad. La denuncia se cursó el 13 de julio de 1683, es decir, a seis días de la subasta45.

Teniers se defendió de estas acusaciones por medio de su abogado, Hoppenbrouwer, quien argumentó que no procedían con arreglo a la ley. En primer lugar, hizo valer la sentencia de 1670 cuyo fallo fue emitido a favor de su representante. Después, defendió los motivos por los que Teniers realizaba la subasta, amparados en la ordenanza local de 9 de septiembre de 1529. Así, en aplicación de la misma, cualquier persona tenía derecho a vender en pública subasta el inventario de bienes de su casa e invitar a cuantas personas considerara oportunas. Según su abogado, todas las pinturas subastadas formaban parte del ajuar de la casa del pintor y este se veía obligado a hacerlo por problemas de liquidez ante el pago de la herencia de sus hijos. Además, era público y notorio cómo los decanos del gremio y los pintores de Bruselas habían acudido a este procedimiento en el pasado, siendo conocidos los casos de Van den Daele, De Crayer, Novelliers y Snyders ${ }^{46}$.

No faltaron sin duda argumentos apelatorios a la buena fe, tales como que su cliente era miembro del gremio a pesar de ser pintor de Corte y estar eximido de ello o las cantidades económicas con las que le había ayudado, incluido el regalo de un vaso dorado. En su defensa, Hoppenbrouwer señaló que la subasta de Teniers suponía beneficios económicos para la ciudad, ya que los potenciales clientes no sólo dejarían dinero en ella, sino que se podrían interesar por la obra de otros maestros. No obstante, todo se fundamentaba en los recelos hacia el pintor y en el desconocimiento del mercado del arte, en esa ignorancia que es enemiga del arte, en palabra de Teniers «Ars non habet inimicum nisi ignorantem» ${ }^{47}$.

No se conoce, en esta ocasión, el resultado del fallo del Consejo Soberano de Brabante, pero la defensa de Teniers deja clara que los beneficios de su posición social, como pintor de Corte, sólo hacían nada más que favorecer al gremio y colo- 
car a Bruselas en el mapa como capital de las artes. En cualquier caso, las relaciones con el gremio de Amberes fueron más fluidas teniendo en cuenta que, gracias a su intercesión con Felipe IV, la ciudad gozó en 1663 de una Real Academia de Bellas Artes.

No cabe la menor duda de que Teniers nunca se achantó ante los miembros del gremio de Bruselas y la venta privada de 1666 no debe fundamentarse ni en prohibiciones gremiales, ni en su renuncia al oficio para poder hacer uso de su escudo de armas. Estas prohibiciones fueron una excusa del pintor para sacar mayor beneficio económico a la venta de sus cuadros, amprándose en fórmulas privadas. Él era consciente de la admiración que sentían propios y extraños por sus producciones. Teniers había desarrollado un género con tal maestría que bastaba un solo rumor de venta de obras en su casa para que curiosos y clientes se desplazaran interesados en «veoir la rareté des peintures».

\section{CONCLUSIONES}

Este trabajo se ha abordado desde la contemplación social y económica del arte en el período que llamamos Siglo de Oro. Así, la figura de Teniers II, inmersa plenamente en el siglo XVII, participa como artista de ese ser social que depende de su clientela y de su público. Sin duda, el pintor flamenco se nutre además de ese proceso de elevación del nivel artístico que, en palabras de Julián Gállego, lo haría pasar de artesano a artista. Sin duda, es un ejemplo de artista que busca ascenso y ennoblecimiento social, cosa que finalmente consiguió. Así, los paralelos con Velázquez no pueden dejar de hacerse hasta el punto de considerar su figura de ayuda de cámara, una suerte de aposentador español, muy superior a la de su oficio como pintor.

La ambición de Teniers II permitió que su taller liderara la red del comercio artístico de la ciudad de Brabante en esa segunda mitad del siglo XVII, lo que motivó enfrentamientos con el gremio de pintores. De ellos, salió airoso. El maestro no dudó en utilizar el mecanismo de la venta privada para obtener un mayor beneficio económico.

Este trabajo ha permitido aportar los nombres de nuevos clientes que "consumieron" la obra de Teniers, bien porque fuera de su gusto o porque les atraía su rareza, siendo la personalidad más destacada la del príncipe don Fernando Alejandro de Portugal. Teniers se sintió solicitado por auténticos connaiseurs dentro de ese ambiente cortesano que domina a la Europa del momento, entre ellos el rey Felipe IV.

Por último, hemos dado a conocer el procedimiento con el que se llevaba a cabo la venta privada de obras de arte fuera de los mecanismos de la subasta pública. En definitiva, el liderazgo de Teniers II en la red económica artística del Siglo de Oro. 


\section{BiBLIOgRAFÍA}

Aterido Fernández, Ángel et al., Inventarios reales. Colecciones de pintura de Felipe $\checkmark$ e Isabel de Farnesio, Madrid, Fundación de Apoyo de la Historia del Arte Hispánico, 2004.

Arias Bonel, José Luis, «El concierto interrumpido de David Teniers II», Goya. Revista de Arte, 307-308, 2005, pp. 265-278.

Bocquet, Louis, David Teniers, París, Éditions Nilsson, 1924.

Bouza, Fernando, «"L'on faict sçavoir que l'on vendrá". El anuncio y catálogo impreso de la subasta de pinturas del Príncipe de Portugal (Bruselas, 1670)», Revista de Emblemática y Cultura Visual, 9, 2017, pp. 39-54.

Callatay, Édouard de, «Études sur les paysagistes bruxellois de XVII siècle», Revue Belge d'Archéologie et Historie de l'Art, XXIX, 1960, pp. 188-203.

Checa Cremades, Fernando, Renacimiento Habsbúrgico. Felipe II y las imágenes artísticas, Valladolid, Universidad de Valladolid, 2017.

Davidson, Jane P., David Teniers the Younger, Boulder, Westview Press, 1979.

Denucé, Jan, Na Peter Pauwel Rubens: Documenten uit den Kunsthandel te Antwerpen in de XVII Eeuw van Matthijs Musson, Amberes, De Sikkel, 1949.

Des Marez, Guillaume, «La maison de David Teniers II et l'hôtel Ravenstein», Annales de la Société Royale d'Archeologie de Bruxelles, 1912, pp. 5-51.

Díaz Padrón, Matías, El siglo de Rubens en el Museo del Prado. Catálogo razonado de pintura flamenca del siglo XVII, Barcelona / Madrid, Editorial Prensa Ibérica / Museo del Prado, 1995.

Díaz Padrón, Matías, y Royo-Villanova, Mercedes, David Teniers, Jan Brueghel y los gabinetes de pinturas, cat. exp., Madrid, Museo Nacional del Prado, 1992.

Dreher, Faith Paulette, «The Artist as Seigneur: Chateaux and Their Propietors in the Work of David Teniers Il», The Art Bulletin, 60, 1978, pp. 682-703.

Frank, Ana Isabel, El «Viaje de España» de Antonio Ponz, Fráncfort del Meno, Peter Lang, 1997.

Galesloot, Louis, «Un procès entre David Teniers II et la corporation des peintres, batteurs d'or et vitriers de Bruxelles», Messager des Sciences Historiques, 1868, pp. 263-283.

García-Frías Checa, Carmen, «David Teniers el Joven en las colecciones reales de Patrimonio Nacional», Reales Sitios. Revista de Patrimonio Nacional, 201, 2015, pp. 17-36.

González Asenjo, Elvira, Don Juan José de Austria y las Artes, 1629-1679, Madrid, Fundación Instituto y Empresa, 2005. 
Haskell, Francis, Patronos y pintores, arte y sociedad en la Italia barroca, Madrid, Cátedra, 1984.

Herrero Carretero, Concha, Catálogo de tapices del Patrimonio Nacional, III, Siglo XVIII. Reinado de Felipe V, Madrid, Patrimonio Nacional, 2000.

Kamp, J. L. J. van de, Emanuel van Portugal en Emilia van Nassau, Assen, Van Gorcum, 1980.

Klinge, Margret, Adriaen Brouwer. David Teniers The Younger, cat. exp., Nueva York, Noortman \& Brod, 1982.

Klinge, Margret, David Teniers the Younger, cat. exp., Gante, Snoeck-Ducaju and Zoon, 1991.

Klinge, Margret, «David Teniers d.J-Theatrum Pictorium», en Krijg en Kunst Leopold Willem (1614-1662). Habsburger, landwoogd en Kunstverzamelaar, cat. exp., ed. Josef Mertens y Franz Aumann, Bilzen, Landcommanderij Alden Biesen, 2003.

Klingle, Margret, y Lüdke, Dietmar, David Teniers der Jüngere 1610-1690. Alltag und Vergnügen im Flandern, cat. exp., Heidelberg, Staatliche Kunsthalle Karlsruhe, 2005.

Madrazo, Pedro, Viaje artístico de tres siglos por las colecciones de cuadros de los Reyes de España, desde Isabel la Católica hasta la formación del Real Museo del Prado de Madrid, Barcelona, Daniel Cortezo y Cía., 1884.

Martín González, Juan José, El artista en la sociedad española del siglo XVII, Madrid, Ensayos de Arte Cátedra, 1984.

Martínez Leiva, Gloria, y Rodríguez Rebollo, Ángel, El inventario del Alcázar de Madrid de 1666: Felipe IV y su colección artística, Madrid, Polifemo, 2015.

Moreno García, María de los Ángeles, «El marqués de Caracena, mecenas de David Teniers el Joven», Goya. Revista de Historia del Arte, 204, 1980, pp. 330-336.

Peyre, Roger, David Teniers, París, Henri-Laurens, 1910.

Pinchart, Alexandre, Archives des arts, sciences et lettres. Documents inédits publiés et annotés par Alexandre Pinchart..., Bruxelles, Imprimerie Eug. Vanderhaeghen, 1860.

Ponz, Antonio, Viaje de España, o cartas en que se da noticia de las cosas más apreciables y dignas de saberse que hay en ellas, Madrid, Joaquín Ibarra, 1772-1794, tomo VI (1776).

Romero Medina, Raúl, y Van Belle, Jean-Louis, «Remédié les pintures entiérement gastèes et faict agrandir les toiles. David Teniers II entre las galerías de pinturas de Coudenberg y Tervueren en la corte de los Habsburgo en Bruselas», en prensa. 
Rosenberg, Adolf, Teniers der Jüngere, Bielefeld / Leipzig, Velhagen und Klasing, 1895.

Urriagli Serrano, Diana, Las colecciones de pintura de Carlos IV en España, Madrid, Fundación Universitaria Española / Seminario de Arte e Iconografía Marqués de Lozoya, 2012.

Vergara, Alejandro, «La pintura en el ámbito de los archiduques», en El arte en la corte de los archiduques Alberto de Austria e Isabel Clara Eugenia (15981633). Un reino imaginado, Madrid, Sociedad Estatal para la Conmemoración de los Centenarios de Felipe II y Carlos V, 2000, pp. 64-81.

Vermoelen, John, «David Teniers et sa famille», Revue historique Nobiliaire, 8, 1870, pp. 3-19.

Vlieghe, Hans, David Teniers the Younger (1610-1690). A Biography, Turnhout, Brepols, 2011.

Werner, Thomas, «La corte de Bruselas y la restauración de la casa de Habsburgo en Flandes, 1598-1631», en El arte en la corte de los archiduques Alberto de Austria e Isabel Clara Eugenia (1598-1633). Un reino imaginado, Madrid, Sociedad Estatal para la Conmemoración de los Centenarios de Felipe II y Carlos V, 2000, pp. 46-63. 